\title{
Preparation and Characterization of Electrodeposited Iron + Cobalt Thin Films from a Chloride Bath
}

\author{
Adriana N. Correia, ${ }^{*}$ Regina C. B. de Oliveira and Pedro de Lima-Neto \\ Departamento de Química Analítica e Físico-Química, Universidade Federal do Ceará, Bloco 940, \\ Campus do Pici, 60455-970, Fortaleza - CE, Brazil
}

\begin{abstract}
Ligas Fe-Co foram depositadas e dissolvidas em solução contendo íons metálicos e em solução de $\mathrm{NH}_{4} \mathrm{Cl}$. Resultados voltamétricos sugerem interação entre os componentes da liga, originando uma solução sólida. Perfis de ALSV apresentam diferenciação para o processo de dissolução dos metais individuais e das ligas, com comportamento semelhante ao observado para cobalto e/ou ferro, com deslocamento de potencial para valores mais positivos à medida que aumenta o teor de cobalto no banho. A análise adimensional dos transientes potenciostáticos para cobalto, ferro e FeCo 1:1 e 1:10 indica processo de nucleação progressiva; já Fe-Co 1:5 segue a curva teórica para nucleação instantânea. A caracterização química e física dos eletrodepósitos mostra dependência entre a morfologia superficial e a composição do banho eletrolítico. Além disto, análises por EDX sugerem que a composição química dos eletrodepósitos foi sempre correspondente à composição do banho eletrolítico. Desta forma, é possível classificar estes processos como deposição regular.
\end{abstract}

Fe-Co alloys were deposited and dissolved in the solution containing metallic ions and in the $\mathrm{NH}_{4} \mathrm{Cl}$ solution. Voltammetric results suggest interaction between the alloy components, constituting a solid solution. ALSV profiles show a differentiation for the dissolution process of the individual metals and alloys, with potentials displacement in the dissolution processes for more and more positive values, as the proportion of cobalt increases in the bath. The nondimensional analyses of the potentiostatic transients for the cobalt, iron and Fe-Co 1:1 and 1:10 suggest a progressive nucleation. However, Fe-Co 1:5 allowed instantaneous nucleation. The chemical and physical characterization of the electrodeposits showed dependence between the surface morphology and the composition of the electrolytic bath. Besides, EDX analyses showed that the composition of the electrodeposits were always corresponding the chemical composition of the electrolytic bath. In this way, it was possible to classify these processes as regular deposition.

Keywords: electrodeposition, anodic dissolution, Fe-Co thin films

\section{Introduction}

The electrodeposition of alloys is a process much more complex than the electrodeposition of pure metals and several binary alloys systems have been investigated and reviewed. ${ }^{1-12}$ Moreover, only few alloys systems have been industrially applied because an adequate control of these complex processes is naturally required in order obtaining a correct understanding of mechanisms. Electrodeposited alloys have potential applications for magnetic shielding, memory devices for computers and recording tapes, for corrosion protection and for electrocatalysis.

\footnotetext{
* e-mail: acorreia@ufc.br
}

Nowadays, the determination of alloy phase structure has been carried out using electrochemical techniques, such as galvanostatic and potentiostatic techniques, and, in most cases, anodic linear sweep voltammetry. ${ }^{13}$

Literature on the electrodeposition of alloys of the iron group metals ( $\mathrm{Ni}, \mathrm{Fe}, \mathrm{Co}$ and $\mathrm{Zn}$ ), is rather extensive, comprising several papers. ${ }^{14-18}$ These alloys have many useful properties such as high internal strength, hardness, high corrosion resistance and unusual magnetic properties. Many magnetic alloys with different compositions are widely employed for various purposes. Ferromagnetic alloys, e.g., Fe-Co and $\mathrm{Fe}-\mathrm{Ni}$ have received considerable attention for their practical applicability in modern industries, such as rocketry, computers, space technology, etc..$^{6,14-16,18-23}$ Myung and Nobe ${ }^{18}$ detected that the corrosion resistance of $\mathrm{Fe}-\mathrm{Co}$ 
alloys were an order of magnitude lower than $\mathrm{Fe}-\mathrm{Ni}$ and Co-Ni. On the other hand, the same authors determined the substantial increase in corrosion resistance by addition of $\mathrm{Ni}$ to $\mathrm{Fe}$-Co deposits and the slight effect on this parameter with addition of B. Lallemand et al. ${ }^{20}$ observed that the codeposition of cobalt and iron leads to a reduction of the reaction rate of the more noble component and an increase of the reaction rate of the less noble component even if organic additives are adsorbed on the electrode surface, and affecting the polarization curves of single metals. ${ }^{23}$

Based on attractive soft magnetic properties and large magnetic inductions, Fe-Co alloys exhibit the largest magnetic induction of any material. ${ }^{24-26}$ At high temperatures, such as $998 \mathrm{~K}$, metallurgical alloys near the equiatomic composition undergo changes in structure from $\alpha$-bcc to $\alpha^{\prime}$-CsCl-type structure. This ordering influences intrinsic magnetic properties slightly. Mattoso et al. ${ }^{19}$ compared the binary phase diagram for electrodeposited $\mathrm{Fe}-\mathrm{Co}$ alloys at room temperature to the equilibrium phase diagram of bulk Fe-Co. They observed relatively large deviations between both phase diagrams, especially the absence of the equilibrium bcc + fcc mixed phase around $80 \%$. The absence of $\mathrm{CsCl}$ ordering around $50 \%$ in the electrodeposited diagram is also observed.

Bento and Mascaro ${ }^{16}$ verified that the iron deposition occurs at more negative potentials than cobalt deposition because cobalt is a nobler metal and established that $\mathrm{Fe}$ Co alloys in 1:1 and 10:1 ratios exhibited an instantaneous nucleation mechanism.

The presence of organic additives containing the sulfonamide group seems to be responsible for the best anti-corrosion properties of the Fe-Co deposit whereas the presence of carbonyl one seems to interfere on material composition. ${ }^{20}$

Kim et al. ${ }^{21}$ studied the electrodeposited Fe-Co from chloride and sulfate baths and suggested that the current efficiencies from chloride bath were significantly higher than that from sulfate one. High current efficiencies, around $52 \%$, was independent of $\mathrm{Fe}^{2+}$ concentration in chloride baths, but decreased to level of $18 \%$ in sulfate baths. These results can be justified by the fact of the chlorine to have catalytic effect through the formation of an ion bridge between the electrode and the metal ion being discharged. Magnetic saturation of $\mathrm{Fe}-\mathrm{Co}$ electrodeposits was independent of anions types and increased with increasing deposit iron content. However, no effects of anion types on the phases and surface morphology in $\mathrm{Fe}-\mathrm{Co}$ electrodeposits were observed.
The aim of this paper is to prepare and to characterize $\mathrm{Fe}-\mathrm{Co}$ thin films obtained from chloride bath on vitreous carbon. The binary Fe-Co alloys were deposited and dissolved by a cathodic and anodic linear sweep potential in the solution containing ions of both metals and in the $\mathrm{NH}_{4} \mathrm{Cl}$ solution, respectively. Another procedure used here was based on potentiostatic transients of current where the dependence between current and experiment time for the formation and growth of a new metallic phase at a constant negative potential is recorded, followed by dissolution of the electrodeposited alloy by anodic linear sweep voltammetry in the $\mathrm{NH}_{4} \mathrm{Cl}$ solution.

\section{Experimental}

Chemicals used here were $\mathrm{FeCl}_{3}, \mathrm{CoCl}_{2}, \mathrm{NaCl}$ and $\mathrm{NH}_{4} \mathrm{Cl}$ (Synth and Fluka). All solutions were freshly prepared with water treated by a Millipore Milli-Q system. The Fe-Co alloy ratios investigated were 1:1, 1:5 and 1:10, where $\mathrm{Fe}^{3+}$ concentration was maintained constant at $0.05 \mathrm{~mol} \mathrm{dm}^{-3}$ and $\mathrm{Co}^{2+}$ concentration varied between $0.05 \mathrm{~mol} \mathrm{dm}^{-3}$ and $0.5 \mathrm{~mol} \mathrm{dm}^{-3}$. A $1.0 \mathrm{~mol}$ $\mathrm{dm}^{-3}$ solution was used for $\mathrm{NaCl}$ and $\mathrm{NH}_{4} \mathrm{Cl}$. All experiments were performed at room temperature (r.t., around $25{ }^{\circ} \mathrm{C}$ ).

The electrochemical experiments were carried out in a conventional three-electrode cell (Pyrex ${ }^{\circledR}$ glass). The working electrode $\left(\mathrm{A}_{\text {geom }}=0.20 \mathrm{~cm}^{2}\right)$ was a vitreous carbon rod (CTA, Brazil) sealed in a Pyrex ${ }^{\circledR}$ tub embedded in an epoxy resin. Vitreous carbon surface was polished before each experiment on emery paper of grade $600(3 \mathrm{M})$. A platinum plate $\left(\mathrm{A}_{\text {geom }}\right.$ $\left.=0.35 \mathrm{~cm}^{2}\right)$ and a saturated calomel electrode were used as a counter and a reference electrode, respectively.

Electrochemical experiments were controlled with a potentiostat PGSTAT30 (Autolab), under a computerized control. The surface morphology of the electrodeposits was examined with a XL-30 (PHILIPS) scanning electron microscope. The qualitative and semi-quantitative chemical analyses of the alloys were performed by energy dispersive X-rays (EDX) in a model QX 2000 (Link Analytical) linked to SEM apparatus.

All voltammetric experiments were performed at $5 \mathrm{mV}$ $\mathrm{s}^{-1}$, scanning at first to negative direction. Only the first cycle was considered in each experiment. The applied potentials for potentiostatic experiments were determined based on the results of voltammetric experiments. Series of potential step experiments at different increments were carried out by stepping from $-0.5 \mathrm{~V}$ (initial potential) to the selected final potential (between $-0.858 \mathrm{~V}$ and $-1.250 \mathrm{~V}$ ). The duration of each potential step was typically $60 \mathrm{~s}$. 


\section{Results and Discussion}

There is no redox reaction on the support electrolyte, $\mathrm{NaCl}$, at the working electrode surface in the potential region where the electroactive species were deposited/ dissolved.

\section{Voltammetric measurements}

Figure 1 shows the cyclic voltammograms obtained for the vitreous carbon electrode in three different electrolytes containing $0.15 \mathrm{~mol} \mathrm{dm}^{-3} \mathrm{NaCl}$ (blank solution, without electroactive species), $0.05 \mathrm{~mol} \mathrm{dm}^{-3}$ $\mathrm{FeCl}_{3}+1.0 \mathrm{~mol} \mathrm{dm}^{-3} \mathrm{NaCl}$ and $0.05 \mathrm{~mol} \mathrm{dm}^{-3} \mathrm{CoCl}_{2}+$ $1.0 \mathrm{~mol} \mathrm{dm}^{-3} \mathrm{NaCl}$. The scan potential rate was $5 \mathrm{mV}$ $\mathrm{s}^{-1}$. In addition to the redox couple at about $-0.4 \mathrm{~V}$, probably due to native quinone groups on the glassy carbon surface, known to be electrocatalytically active, the voltammograms obtained show the presence of cathodic and anodic processes inherent to deposition and dissolution of metals. In this figure it can observed in the cathodic scan that the cobalt deposition occurs prior to iron deposition, exhibiting a well-defined reduction process at $-0.88 \mathrm{~V}$. This fact is not observed for iron, mainly due to simultaneous hydrogen evolution. In the anodic scan, there is one dissolution process for each system (maximum for $\mathrm{Fe}$ is at $-0.51 \mathrm{~V}$ and for $\mathrm{Co}$ is at $-0.34 \mathrm{~V})$. The codeposition of the iron-group metals is characterized by the anomalous process. The standard equilibrium potentials of the cobalt and iron are, respectively, $-0.28 \mathrm{~V}$ and $-0.04 \mathrm{~V}$ (in function of SHE). Thus, from thermodynamic considerations, it would be expected that the deposition sequence would be cobalt then iron. In spite of the kinetics of the electrodeposition for individual metals establishes that the rates follow

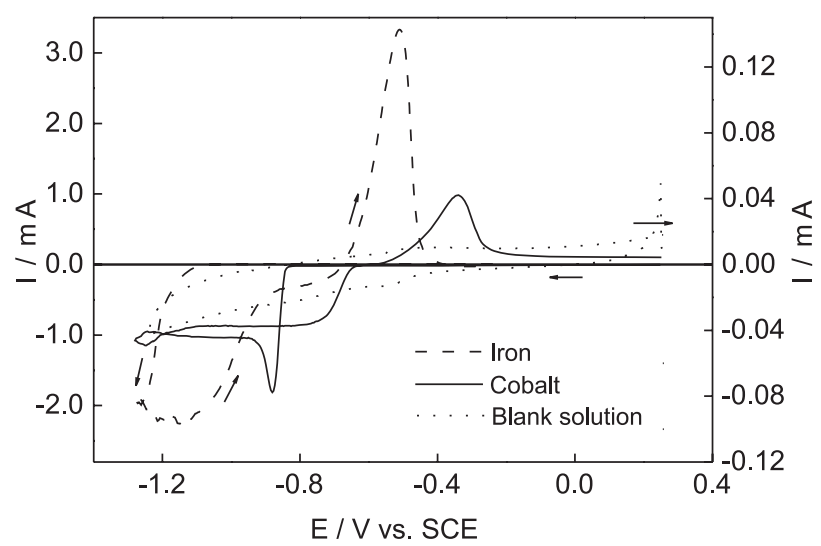

Figure 1. Cyclic voltammograms for blank solution (dotted line) and for electrodeposition and electrodissolution of iron (dashed line) and cobalt (solid line) on vitreous carbon electrode in $1.0 \mathrm{~mol} \mathrm{dm}^{-3} \mathrm{NaCl}$ bath at 5 $\mathrm{mV} \mathrm{s}^{-1}$. Lower limit of potential sweep is $-1.28 \mathrm{~V}$. the standard equilibrium potentials, in this work there is an inversion with cobalt being deposited preferentially. Due to differences in deposition and dissolution potentials, a crossover occurs between the cathodic and anodic branches, being a diagnostic for the nuclei formation on the electrode.

In order to evaluate the influence of cobalt concentration at the Fe-Co alloys formation, Figure 2 presents the voltammetric results for 1:1, 1:5 and 1:10 Fe:Co ratios. It can be observed that there is a positive shift in the peak potential, about $400 \mathrm{mV}$, in the dissolution processes as the amount of cobalt increases in the bath composition. This is an indication that the alloys with high cobalt content are nobler, since dissolution occurs at more positive potentials. The observed change in the maximum current can be due to a change in the loaded layer. The total concentration of the metal ions in solution increases from $0.10 \mathrm{~mol}$ $\mathrm{dm}^{-3}$ to $0.55 \mathrm{~mol} \mathrm{dm}^{-3}$ as the cobalt concentration increases. Thus, the amount of electrodeposited material is changed for higher values. From Faraday's law, the variation of thickness in function of the cobalt content was calculated and the values obtained were: $0.57 \mu \mathrm{m}$ for Fe-Co 1:1, $0.78 \mu \mathrm{m}$ for Fe-Co 1:5 and 1.56 $\mu \mathrm{m}$ for Fe-Co 1:10.

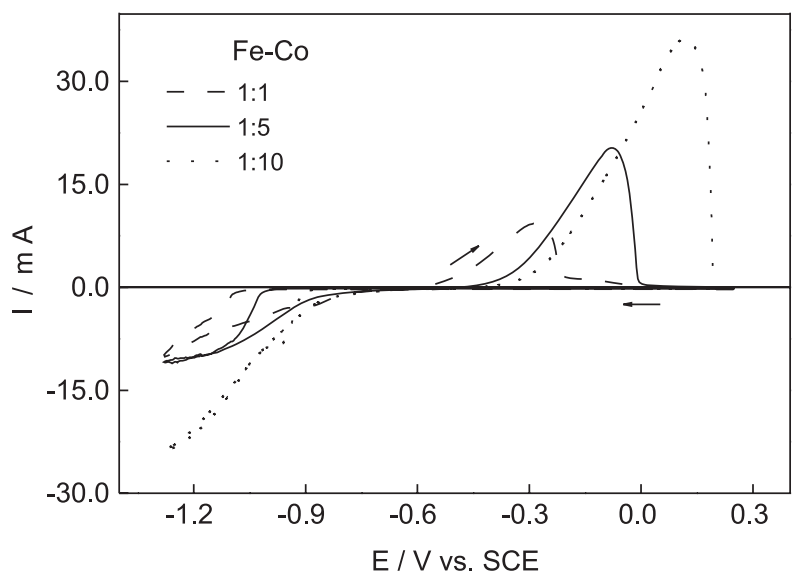

Figure 2. Cyclic voltammograms for electrodeposition and electrodissolution of Fe-Co 1:1 (dashed line), Fe-Co 1:5 (solid line) and Fe-Co 1:10 (dotted line) on vitreous carbon electrode in $1.0 \mathrm{~mol} \mathrm{dm}^{-3}$ $\mathrm{NaCl}$ bath at $5 \mathrm{mV} \mathrm{s}^{-1}$. Lower limit of potential sweep is $-1.28 \mathrm{~V}$.

The voltammetric profile for iron commenced and terminated at $-0.25 \mathrm{~V}$, while for cobalt and Fe-Co alloys this value is equal to $0.25 \mathrm{~V}$. In all the cases $-1.28 \mathrm{~V}$ is the inversion potential. There was not significant current produced initially, until potentials of $-1.10 \mathrm{~V}$ for iron, -1.06 V for Fe-Co 1:1, -1.00 V for Fe-Co 1:5, -0.88 V for Fe-Co 1:10 and $-0.80 \mathrm{~V}$ for cobalt were reached. At these values, the cathodic current begins to increase until to form the reduction processes. 


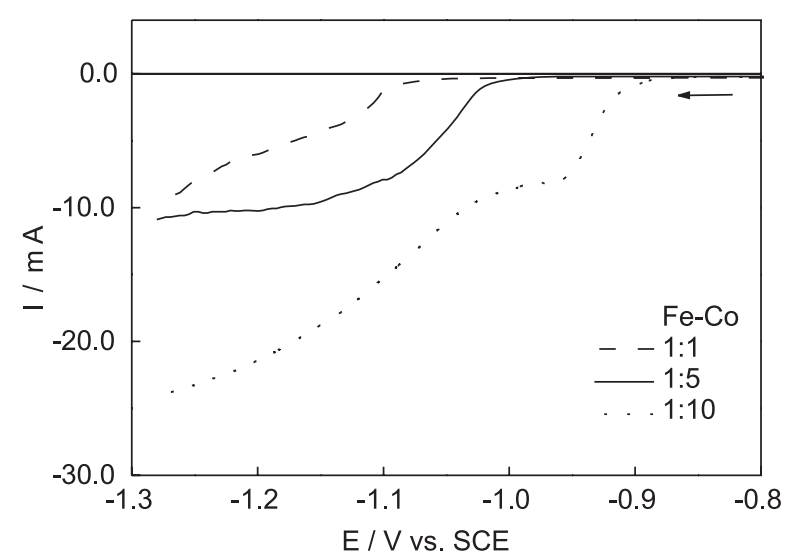

Figure 3. Zoomed details at the beginning of the electrodeposition process of Fe-Co 1:1 (dashed line), Fe-Co 1:5 (solid line) and Fe-Co 1:10 (dotted line) on vitreous carbon electrode in $1.0 \mathrm{~mol} \mathrm{dm}^{-3} \mathrm{NaCl}$ bath at 5 $\mathrm{mV} \mathrm{s}^{-1}$. Lower limit is $-1.28 \mathrm{~V}$.

By enlarging the deposition region for alloy systems, as showed in Figure 3, it can be seen that the presence of cobalt ions influences the beginning of the reduction process. The reduction potentials are shifted towards more positive values when the cobalt content is higher.

\section{Chronoamperometric measurements}

Chronoamperometry was used to study the electrocrystallization process of $\mathrm{Fe}, \mathrm{Co}$ and their alloys. Based on the voltammetric experiments it was possible to define a suitable potential range to promote potentiostatic deposition. Figure 4 presents the family of current-time transients and the potential jumps were performed from $-0.5 \mathrm{~V}$ to more negative potential values indicated in the caption of this figure. The experimental profiles show typical nucleation and growth features, although they are roughly different. The ascendant part of current-time transients increases until it reaches a maximum (no welldefined in some cases) when diffusion becomes the ratelimiting process.

We further assume that the process of electrocrystallization occurs by the model of threedimensional nucleation and growth and that the clusters of the new phase have a hemispherical shape. The small amplitude cathodic polarization will continue the process of surface renewal and further improve the reproducibility of the measurements. Unlike the experiments in which a large number of nuclei are formed shortly after the beginning of the transient, for these potentiostatic steps an "induction time" is observed. The induction time is a direct consequence of the need of clusters of ad-atoms to grow to a critical size required for the onset of the
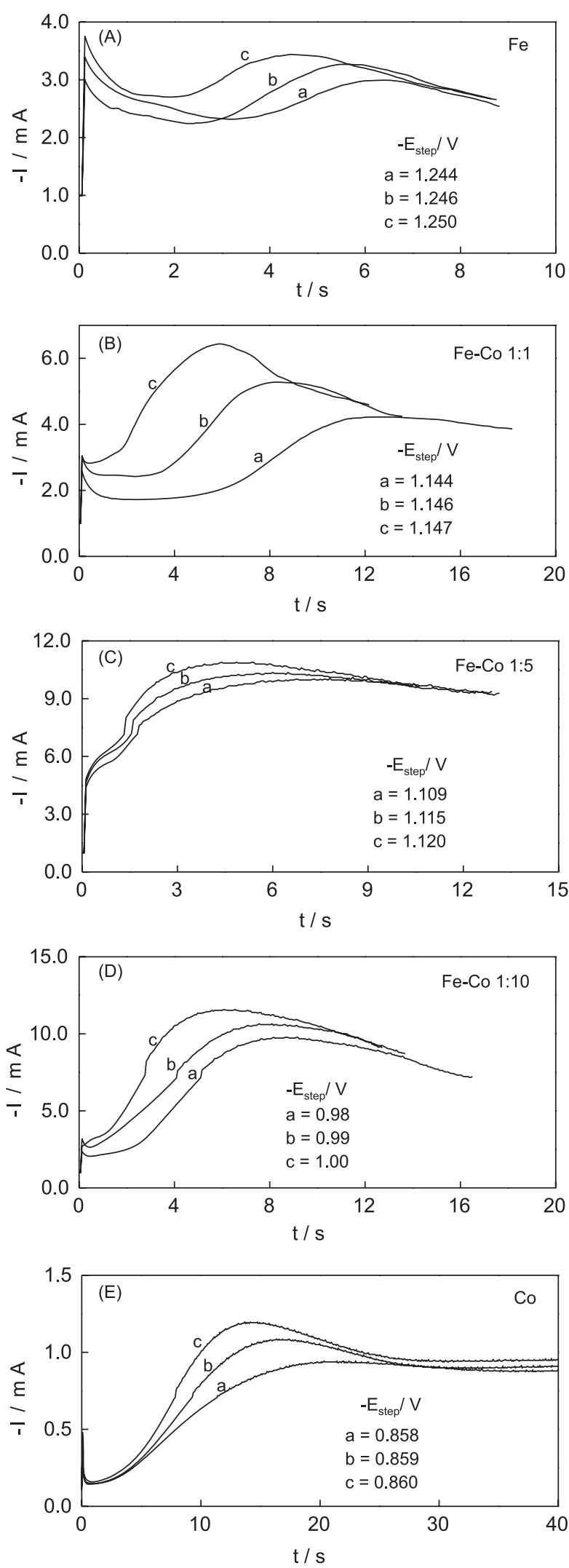

Figure 4. Potentiostatic transients for (A) Fe; (B) Fe-Co 1:1; (C) Fe-Co 1:5; (D) Fe-Co 1:10 and (E) Co. Step potentials are indicated in the figure. 
new phase, being inversely dependent of the applied potential step.

Analyses of experimental data were realized and the best fitting obtained was based on 3D diffusion-controlled nucleation and growth mechanism developed by Scharifker and Hills. ${ }^{27}$ The basic equations described in this model are displayed in Table 1.

Figure 5 displays the normalized coordinates of experimental current-time transients with the corresponding theoretical curves for instantaneous and progressive 3D nucleation and growth controlled by diffusion. It can be seen, for all studied deposition potentials, that Fe, Fe-Co 1:1, Fe-Co 1:10 and Co show good agreement with theoretical curves for progressive process, while $\mathrm{Fe}-\mathrm{Co}$ 1:5 results were fitted with theoretical curves for instantaneous process. Since the hydrogen reduction reaction can be considered as a possible influence at the systems, some explanations have to be sought in order to justify this change. (i): in spite of the surface of vitreous carbon electrode inhibits hydrogen evolution reaction at highly negative potentials, an electroactive site can serve as catalytic centre for this reaction; (ii) a result like this can be explained by determining the phase composition and structure of the film. According to Mattoso et al. ${ }^{19}$ it can be considered by $\mathrm{X}$-rays diffraction studies for $\mathrm{Fe}_{1-\mathrm{x}}-\mathrm{Co}_{\mathrm{x}}$ electrodeposited alloys that there is only one peak attributed to the body-centered cubic (bcc) structure up to $\mathrm{x}=85 \%$, some vestiges of a transition region with bcc and fcc structure at $\mathrm{x}=87.5 \%$ and that the spectrum of $\mathrm{Fe}_{10} \mathrm{Co}_{90}$ shows two peaks indicating a pure face-centered cubic phase. Beyond the catalytic effects, we can assume that the Fe-Co 1:5 alloy presented this change in the mechanism based on the existence of this transition region.

As the experimental values for $i_{\max }^{2} t_{\max }$ stayed approximately constant for the iron $\left(4.66 \times 10^{-4}<i_{\max }^{2} t_{\max }\right.$ $\left.<5.31 \times 10^{-4}\right)$ and cobalt $\left(1.38 \times 10^{-3}<i_{\max }^{2} t_{\max }<1.55 \times\right.$ $10^{-3}$ ) electrodeposition, the diffusion coefficients can be calculated by the equation: ${ }^{27}$

$i_{\text {max }}^{2} t_{\text {max }}=0.2598(z F c)^{2} D$

In this way, the obtained values were $6.8 \times 10^{-6} \mathrm{~cm}^{2}$ $\mathrm{s}^{-1}$ for iron and $5.2 \times 10^{-6} \mathrm{~cm}^{2} \mathrm{~s}^{-1}$ for cobalt. These values are according values reported in literature for iron, i.e., between $9 \times 10^{-6}$ and $5 \times 10^{-5} \mathrm{~cm}^{2} \mathrm{~s}^{-1}$, and for cobalt, i.e., $1.8 \times 10^{-5} \mathrm{~cm}^{2} \mathrm{~s}^{-1} \cdot 28-30$

With these values and through the equation showed in Table 1, it was possible to determinate the rate of nuclei formation for nucleation and growth processes, showed
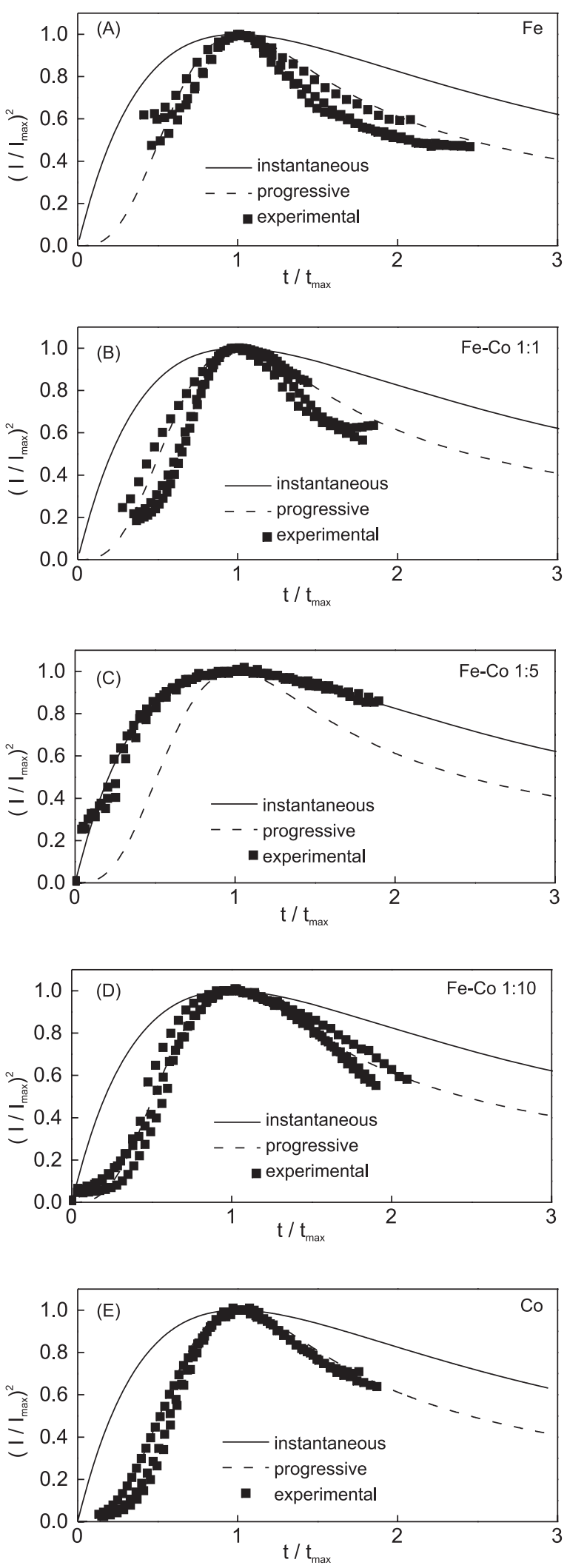

Figure 5. Non-dimensional curves for electrocrystallization of (A) iron; (B) Fe-Co 1:1; (C) Fe-Co 1:5; (D) Fe-Co 1:10 and (E) cobalt, following of theoretical profiles for instantaneous and progressive nucleation. 
Table 1. Preparation and characterization of electrodeposited iron + cobalt thin films from a chloride bath

\begin{tabular}{cc}
\hline Instantaneous Nucleation & Progressive Nucleation \\
$I=\frac{z F \pi(2 \mathrm{Dc})^{3 / 2} M^{1 / 2} N}{\rho^{I / 2}} t^{1 / 2}$ & $I=\frac{2 z F \pi(2 D c)^{3 / 2} M^{1 / 2} A N_{\infty}}{3 \rho^{1 / 2} t^{3 / 2}}$ \\
$\left(\frac{I}{I_{\max }}\right)^{2}=\frac{1.2254}{t / t_{\max }}\left\{1-\exp \left[-2.3367\left(t / t_{\max }\right)^{2}\right]\right\}^{2}$ & $\left(\frac{I}{I_{\max }}\right)^{2}=\frac{1.9542}{t / t_{\max }}\left\{1-\exp \left[-1.2564\left(t / t_{\max }\right)\right]\right\}^{2}$ \\
\hline
\end{tabular}

in Table 2. As expected, the values of $\mathrm{AN}_{\infty}$ increase as the potential values became more negative, once it increases the amount of available energy for the nucleation and growth processes of a new metallic phase. For iron, the values of $\mathrm{AN}_{\infty}$ varied among $23.3 \times 10^{6} \mathrm{~cm}^{-2} \mathrm{~s}^{-1}$ and $43.2 \times$ $10^{6} \mathrm{~cm}^{-2} \mathrm{~s}^{-1}$. Already for cobalt this variation was among $8.7 \times 10^{6} \mathrm{~cm}^{-2} \mathrm{~s}^{-1}$ and $17.1 \times 10^{6} \mathrm{~cm}^{-2} \mathrm{~s}^{-1}$.

Table 2. Preparation and characterization of electrodeposited iron + cobalt thin films from a chloride bath

\begin{tabular}{lccccc}
\hline System & $\begin{array}{c}\mathrm{t}_{\max } \\
(\mathrm{s})\end{array}$ & $\begin{array}{c}-\mathrm{E}_{\text {step }} \\
(\mathrm{V})\end{array}$ & $\begin{array}{c}10^{3} i_{\max } \\
\left(\mathrm{A} \mathrm{cm}^{-2}\right)\end{array}$ & $\begin{array}{c}10^{4} i_{\max }^{2} t_{\max } \\
\left(\mathrm{A}^{2} \mathrm{~cm}^{-4} \mathrm{~s}\right)\end{array}$ & $\begin{array}{c}10^{-6} \mathrm{AN}_{\infty} \\
\left(\mathrm{cm}^{-2} \mathrm{~s}^{-1}\right)\end{array}$ \\
\hline Cobalt & 20.4 & 0.858 & 4.7 & 4.5 & 8.7 \\
& 16.8 & 0.859 & 5.4 & 4.9 & 12.8 \\
& 14.4 & 0.860 & 6.0 & 5.2 & 17.1 \\
Iron & 6.3 & 1.244 & 15.0 & 14.2 & 23.3 \\
& 5.6 & 1.246 & 16.4 & 15.1 & 34.8 \\
& 4.5 & 1.250 & 17.2 & 13.3 & 43.2 \\
\hline
\end{tabular}

\section{Potentiodynamic stripping measurements}

Anodic linear sweep voltammetry (ALSV) was used to characterize the iron + cobalt thin films, supported by morphological observations and by composition determination. Initially, the electrodeposits were acquired in chloride medium containing $\mathrm{Fe}^{3+}$ and/or $\mathrm{Co}^{2+}$ in the established ratios at different step potentials (between $0.858 \mathrm{~V}$ and $-1.250 \mathrm{~V}$ ) during current-time transients. Potentiodynamic stripping in $0.5 \mathrm{~mol} \mathrm{dm}^{-3} \mathrm{NH}_{4} \mathrm{Cl}$ electrolyte was used to analyze the electrodeposits. This procedure allowed a comparison between the dissolution processes of the individual metals and its alloys in the presence (vide Figures 1 and 2) and in the absence of the electroactive species. The initial potentials employed were similar to the step potentials and the final potentials were always equal to $0.8 \mathrm{~V}$.

For all metal ion ratios in working solution the potentiodynamic stripping voltammograms, showed in

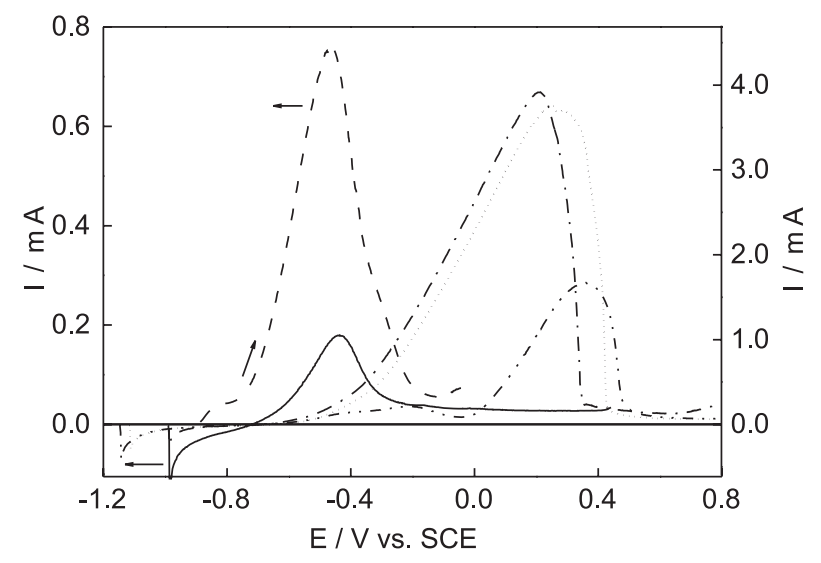

Figure 6. ALSV voltammograms of thin solid films of Fe-Co alloys in $\mathrm{NH}_{4} \mathrm{Cl}$ solution. Alloys were deposited from $\mathrm{NaCl}$ bath at different step potentials during $60 \mathrm{~s}$. Iron (dashed line), Fe-Co 1:1 (dash-dot-dot line), Fe-Co 1:5 (dotted line), Fe-Co 1:10 (dash-dot line) and cobalt (solid line).

Figure 6, revealed a well-defined oxidation process at more positive potentials than those detected for iron and cobalt. It can be observed that the Fe-Co alloys present dissolution processes at more and more positive potentials as the cobalt content is reduced in the electrodeposition bath. As can be seen, this process with only a single peak suggests the dissolution of the solid solution, indicating the existence of a single phase with the more noble metal being reprecipitated on the spot. Also, by Faraday's law, the variation of thickness in function of the cobalt content was calculated and the values obtained were: $0.08 \mu \mathrm{m}$ for Fe-Co 1:1, $0.25 \mu \mathrm{m}$ for Fe-Co 1:5 and $0.24 \mu \mathrm{m}$ for Fe-Co $1: 10$.

Table 3. Preparation and characterization of electrodeposited iron + cobalt thin films from a chloride bath

\begin{tabular}{lcccc}
\hline System & \multicolumn{2}{c}{ Theoretical } & \multicolumn{2}{c}{ Experimental } \\
& $\% \mathrm{Fe}$ & $\% \mathrm{Co}$ & $\% \mathrm{Fe}$ & $\% \mathrm{Co}$ \\
\hline Pure Fe & 100.0 & 0 & 100.0 & 0 \\
Fe-Co $1: 1$ & 50.0 & 50.0 & $30.8 \pm 12.3$ & $69.2 \pm 12.5$ \\
Fe-Co $1: 5$ & 16.7 & 83.3 & $15.6 \pm 1.7$ & $84.4 \pm 1.2$ \\
Fe-Co $1: 10$ & 9.1 & 90.9 & $9.9 \pm 0.9$ & $90.1 \pm 0.9$ \\
Pure Co & 0 & 100.0 & 0 & 100.0 \\
\hline
\end{tabular}




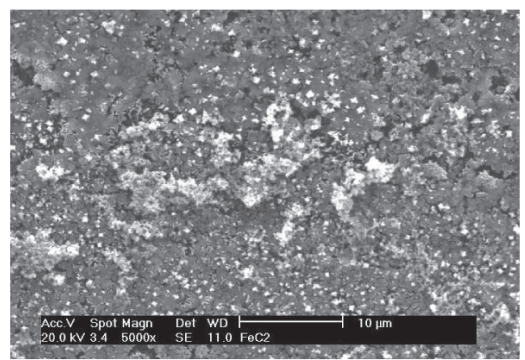

(A)

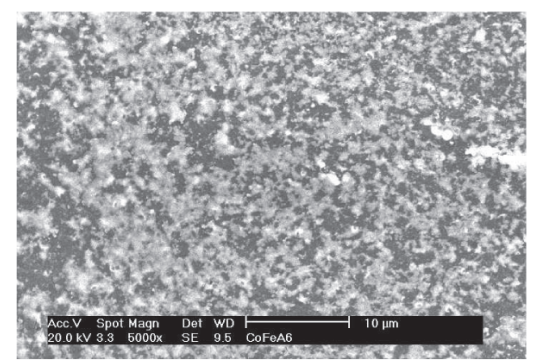

(B)

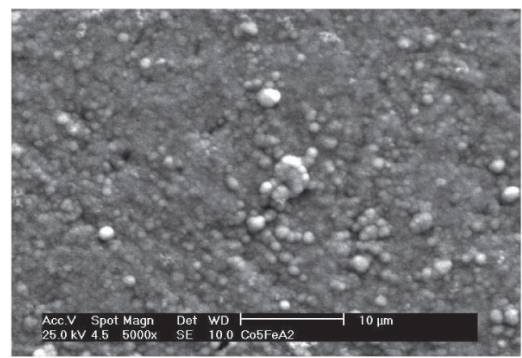

(C)

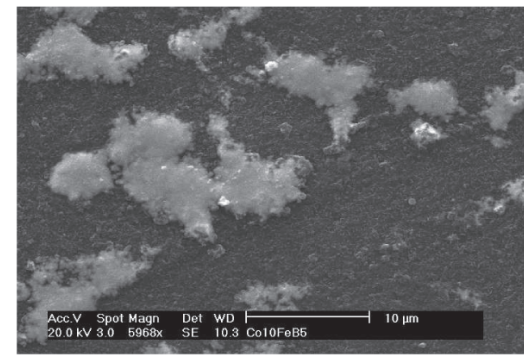

(D)

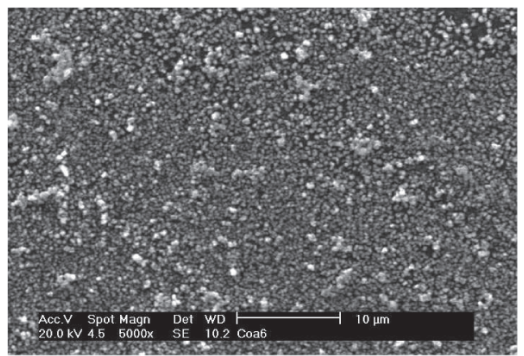

(E)

Figure 7. Scanning electron micrographs of metals and alloys electrodeposits on vitreous carbon electrode obtained by current-time experiments during 60 s. (A) iron at -1.246 V; (B) Fe-Co 1:1 at -1.146 V; (C) Fe-Co 1:5 at -1.115 V; (D) Fe-Co 1:10 at $-0.990 \mathrm{~V}$ and (E) cobalt at $-0.859 \mathrm{~V}$.

\section{Characterization of the deposits}

Finally, the characterization of electrodeposits obtained under these experimental conditions was performed using scanning electron microscope and energy dispersive $\mathrm{X}$-rays analyses aiming the observation of the morphological aspects of these thin metallic films. The results are illustrated in the Figure 7 and in the Table 3. The obtained images suggest the formation of crystals with different morphologies in function of the composition of the electrodeposits. By the EDX analyses it was possible to observe that the metallic content in the electrodeposits is directly related with the bath composition. In this way, when there is an increase of the cobalt content in the bath, the percentage of cobalt in the electrodeposits increases in the same ratio, making possible the classification of the electrodeposition processes studied here as regular.

\section{Conclusions}

Voltammetric results suggest interaction among the alloy components, constituting a solid solution. ALSV profiles show a differentiation for the dissolution process of the individual metals and alloys when dissolved in $\mathrm{NH}_{4} \mathrm{Cl}$. Alloys dissolved in complexing bath present similar behavior to cobalt and/or iron, with potentials displacement in the dissolution processes for more and more positive values, as the proportion of cobalt increases in the bath.
The non-dimensional analyses of the potentiostatic transients for the cobalt, iron and Fe-Co 1:1 and 10:1 deposition suggest a process of nucleation progressive. However, Fe-Co 5:1 allowed instantaneous nucleation. The absence of two current maxima when the supplied energy was enough for the $\mathrm{Co}^{2+}$ and $\mathrm{Fe}^{3+}$ electrodeposition indicates the formation of a solid solution in all the alloy ratios $\mathrm{Fe}$-Co studied here. As expected, the values of $\mathrm{AN}_{\infty}$ and $\mathrm{N}$ increased as the overpotential values became more negative, once it increases the amount of available energy for the nucleation and growth processes of a new metallic phase.

The physical characterization of the electrodeposits showed dependence between the surface morphology and the composition of the electrolytic bath. Besides, EDX analyses showed that the composition of the electrodeposits were always corresponding the composition of the electrolytic bath. In this way, it was possible to classify these processes as regular.

\section{Acknowledgments}

The authors are indebted to the CNPq, CAPES and FINEP. R.C.B. de Oliveira thanks to PIBIC-CNPq for the scholarship.

\section{References}

1. Jovic, V. D.; Tosic, N.; J. Electroanal. Chem. 1998, 441, 69.

2. Armyanov, S.; Electrochim. Acta 2000, 45, 3323. 
3. Correia, A. N.; Machado, S. A. S.; Electrochim. Acta 2000, 45, 1733.

4. Müller, C.; Sarret, M.; Benballa, M.; Electrochim. Acta 2001, 46, 2811.

5. Bajat, J. B.; Miskovic-Stankovic, V. B.; Maksimovic, M. D.; Drazic, D. M.; Zec, S.; Electrochim. Acta 2002, 47, 4101.

6. Mohaidat, Q. I.; Al-Omari, I. A.; Mahmood, S. H.; Physica B 2002, 321, 149.

7. Cavallotti, P. L.; Vicenzo, A.; Bestetti, M.; Franz, S.; Surf. Coat. Technol. 2003, 169-170, 76.

8. Gómez, E.; Pellicer, E.; Vallés, E.; J. Electroanal. Chem. 2003, 556, 137.

9. Gómez, E.; Kipervaser, Z. G.; Vallés, E.; J. Electroanal. Chem. 2003, 557, 9.

10. Correia, A. N.; Machado, S. A. S.; J. Appl. Electrochem. 2003, 33, 367.

11. Marinho, F. A.; Santana, F. S. M.; Vasconcelos, A. L. S.; Santana, R. A. C.; Prasad, S.; J. Braz. Chem. Soc. 2002, 13, 522.

12. Prasad, S.; Marinho, F. A.; Santana, F. S. M.; Braz. J. Chem. Eng. 2000, 17, 423.

13. Despic, A. R.; Jovic, V. D. In Modern Aspects of Electrochemistry; White, R. E.; Bockris, J. O’M.; Conway, B. E., eds.; Plenum Press: New York, 1995, vol. 27, p.143.

14. Djokic, S. S.; Maksimovic, M. D. In Modern Aspects of Electrochemistry; White, R. E.; Bockris, J. O’M.; Conway, B. E., eds.; Plenum Press: New York, 1992, vol. 22, p.417.

15. Ricq, L.; Lallemand, F.; Gigandet, M. P.; Pagetti, J.; Surf. Coat. Technol. 2001, 138, 278.

16. Bento, F. R.; Mascaro, L. H.; J. Braz. Chem. Soc. 2002, 13, 502.
17. Jartych, E.; Jalochowski, M.; Budzynski, M.; Appl. Surf. Sci. 2002, 193, 210.

18. Myung, N. V.; Nobe, K.; J. Electrochem. Soc. 2001, 148, C136.

19. Mattoso, N.; Fernandes, V.; Abate, M.; Schreiner, W. H.; Mosca, D. H.; Electrochem. Solid-State Lett. 2001, 4, C20.

20. Lallemand, F.; Ricq, L.; Berçot, P.; Pagetti, J.; Electrochim. Acta 2002, 47, 4149.

21. Kim, D.; Park, D-Y.; Yoo, B. Y.; Sumodjo, P. T. A.; Myung, N. V.; Electrochim. Acta 2003, 48, 819.

22. Bai, A.; Hu, C-C.; Electrochem. Commun. 2003, 5, 78.

23. Lallemand, F.; Ricq, L.; Wery, M.; Berçot, P.; Pagetti, J.; Appl. Surf. Sci. 2004, 228, 326.

24. Turgut, Z.; Huang, M.-Q; Gallagher, K.; McHenry, M. E.; Majetich, S. A.; J. Appl. Phys. 1997, 81, 4039.

25. Cohen, N. S.; Pankhurst, Q. A.; Barquín, L. F.; J. Phys.: Condens. Matter 1999, 11, 8839.

26. Yu, R. H.; Basu, S.; Ren, L.; Zhang, Y.; Parvizi-Majidi, A.; Unruh, K. M.; Xiao, J. Q.; IEEE Trans. Magn. 2000, 36, 3388.

27. Scharifker, B.; Hills, G.; Electrochim. Acta 1983, $28,879$.

28. Weber, J.; Samec, Z.; Marecek, V.; J. Electroanal. Chem. 1978, 89, 271.

29. Langmaier, J.; Trojanek, A.; Weber, J.; Samec, Z.; J. Electroanal. Chem. 1999, 469, 11.

30. Soto, A. B.; Arce, E. M.; Palomar-Pardavé, M.; González, I.; Electrochim. Acta 1996, 41, 2647.

Received: May 9, 2005 Published on the web: December 1, 2005 